\title{
Clinical Observation after Multifocal Intraocular Lens
}

\section{Implantation}

\author{
Ying Wang and Feng $\mathrm{Ke}^{*}$ \\ Department of Ophthalmology, Renmin Hospital, Hubei University of Medicine, Shiyan,Hubei, China \\ Corresponding E-mail: hubeiwenbo@163.com
}

\begin{abstract}
Objective: To evaluate the binocular vision function, validity and safety of implanted multifocal intraocular lens eye. Method: ultrasonic emulsified combined ReSTOR multifocal intraocular lens implantation surgeries were conducted for 25 eyes of 21 patients, including 17 patients with monocular surgeries and 8 patients with binocular surgeries. Then, patients' post-operation distant and near visions, far and near visual functions and stereoscopic visual function were observed; the off-glasses rate, poor vision and satisfaction [1] were invested through questionnaires. The post-operation follow-up lasted for 3 to 18 months. Result: the distant and near visions of naked eyes of patients implanted with ReSTOR intraocular lens are respectively $0.84 \pm 0.20$ and $0.62 \pm 0.27$ for 3 months after surgeries; all patients have good near and far stereoscopic visual functions; the satisfaction about moderate-distance vision is $84.6 \%(21 / 25)$; the satisfaction about near vision is $93 \%$; the near-vision off-glasses rate is $88 \%(25 / 22)$. Conclusion: multifocal intraocular lens can provide good distant and near visions, far, near and stereoscopic visual functions for patients; the patients implanted such lens in both their eyes can recover the stereoscopic visual function and their vision satisfaction is higher than that of patients implanted such lens in one of their eyes.
\end{abstract}

Keywords. Multifocal intraocular lens, implantation, post-operation effect.

\section{Experimental material and method}

\subsection{Material}

A whole cluster of 21 patients with cataract and 25 eyes from January 2013 and December 2014 in the hospital were selected; the ages of patients were between 25 and 75 years old (average age: $58 \pm 14$ ). Inclusion criteria: the patients' best corrected visual acuity is within 4.7 ; corneal astigmatism $\leqq 1.5 \mathrm{D}$; pre-operation vision: index $\sim 0.4$; nuclear hardness: Class II -IV. Patients with other lesions in their eyes should be excluded. Preoperative examination: vision, corrected visual acuity (CVA), intraocular pressure, A ultrasound, B ultrasound, corneal endothelial cell counting, corneal curvature, corneal topography, IOL-master, OCT, ocular anterior segment photographing, and lacrimal passage irrigation [2]. Materials and devices: Infiniti Vision system ultrasonic emulsifying machine and AcrysofReSTOR SN6A0D1 multifocal intraocular lens. All patients included had no severe physical illness so there's no contraindication in surgeries. 


\subsection{Method}

In order to reduce errors in experimental results caused by human factors during operations, all operations were conducted by one doctor. Compound tropicamide was used for sufficient mydriasis; then, Benoxil eye drops were used in the eyes with operation at intervals for three times in total; the eye drops were used once every ten minutes. The eyes with operation were disinfected paved with cloth. The operative field needed to be fully exposed. In the axial direction of high curvature of cornea, a one-off incision scalpel was used to cut a main transparent corneal incision with a width of $2.2 \mathrm{~mm}$ and a length of about $2.0 \mathrm{~mm}$ from the corneal limbus; then, viscoelastic agent was injected into the anterior chamber; an auxiliary corneal incision was made; the lens anterior capsule was continuously and annularly tore in the middle till the opening diameter was about $5.5 \mathrm{~mm}$; then, hydro dissection was conducted; the lens nucleus piece ultrasonic emulsified aspiration was made with the Infiniti Vision system ultrasonic emulsifying machine; later, the rest cortex was gettered with I/A; the viscoelastic agent was injected into the capsular bag; then, the intraocular lens was implanted and its position is adjusted so that it could be in the center; next, the viscoelastic agent was completely gettered and the incision was closed. The TobraDex eye ointment was applied and the eye with operation was covered [3].

\section{Experimental result and discussion}

\subsection{Result}

The vision for $3 \mathrm{~m}$ after operation: the patients' average distant naked vision is $0.84 \pm 0.20$ and their average near naked vision is $0.62 \pm 0.27$. Their postoperative corrected distance visual acuity spherical equivalents are $-0.50 \sim+0.25$, which are approximate to the pre-conceived refractive state of $0.25 \sim+0.25 \mathrm{D}$. The specific vision distribution of patients after three months is shown in Table 1.

Table 1. Vision Distribution of Patients after Three Months.

\begin{tabular}{|c|c|c|c|c|c|c|}
\hline \multirow{2}{*}{$\begin{array}{c}\text { Total } \\
\text { number of }\end{array}$} & \multicolumn{3}{|c|}{ Far naked vision distribution } & \multicolumn{3}{c|}{ Near naked vision distribution } \\
\cline { 2 - 7 } eyes & $<05$ & $05 \sim 0.9$ & $\geqq 1.0$ & $\leqq 0.33$ & $0.4 \sim 0.9$ & $\geqq 1.0$ \\
\hline 25 & 1 & 17 & 7 & 3 & 18 & 4 \\
\hline
\end{tabular}

All patients have good far and near stereoacuities of naked eyes as well as the near stereoacuity under the corrected near visual acuity.

Postoperative off-glasses rate for $3 \mathrm{~m}$ after operation. According to the investigation of patients' degree of dependence on glasses through questionnaires, 22 patients (88\%) totally take off their glasses.

As for postoperative long-distance vision, patients' satisfaction is $95 \%$; as for postoperative moderate-distance vision in doing housework, vegetable washing, cutting and cooking, and walking upstairs and downstairs, the satisfaction is $84.6 \%(21 / 25)$; as for short-distance vision in book and newspaper reading, using mobile phone and reading labels in the supermarket, the satisfaction is $93 \%$. This result is consistent with that found in researches and investigations at home and abroad; namely, after implantation of ReSTORMIOL, the patients' satisfaction about the moderate-distance vision is lower than the satisfactions about the far and near visions of naked eyes.

Postoperative poor vision symptoms and questionnaire survey on patients' glare for $3 \mathrm{~m}$ after operation: most patients suffered halation in early days after operation but this didn't influence their life and work. 2 patients suffered the night glare and 1 patient felt shadows when watching the mobile phone; but all such symptoms disappeared 2 months after operation. The stereoscopic visual functions of patients with one of their eyes implanted with lens were recovered but 
such patients' vision satisfaction is slightly poorer than that of patients with both their eyes implanted with lens; there's no increase in the poor vision symptom.

\subsection{Discussion}

Although patients can completely have their far vision recovered after single-focus intraocular lens (intraocularlens, SIOL) implantation operation after the traditional cataract operation, the monofocal IOL fails to provide sufficient near vision; for this reason, patients usually need to wear low-degree spectacles for hypermetropia to watch near things and read books. The methods to solve this problem include: monovision, adjustable IOL and multifocal IOL [4,5,6]. Monovision is to implant IOL in the dominant eye for far vision and implant IOL in the non-dominant eye for near and moderate vision. However, not all people can accept mono vision due to the loss of perception of depth. The clinical application of multifocal intraocular lens (MIOL) helps patients with cataract to obtain rather satisfactory far, near and moderate visions. Such lens implanted in the eyes can provide two focuses for near and far visions so the patient's near vision ability is greatly enhanced, compared with the monofocal IOL [7]. According to the optical imaging principle, the MIOLs mainly include DMIO, RMIO and mixed type of DMIO and RMIO [8].

After cataract operation, a patient can get the regulating function similar to that of a human eye. The research in the direction of intraocular lens is always to get rid of the limitation of single-point focusing of intraocular lens, which is also a project researched for years $[9,10,11]$. At present, the application of MIOL is the best way to solve the loss of accommodation power after cataract operation $[12,13,14]$. Through its special design, the MIOL greatly improves the postoperative vision quality of patients with cataract and effectively enhances their off-glasses rate.

The application of MIOL largely improves patients' functional vision and greatly enhances their living quality, so it provides an important direction for the current ophthalmic medical technology $[15,16,17]$. However, we should also know that superficial vision is not always directly related to the patient's daily functional vision. As MIOL cannot provide the best focus at all sorts of functional distances and MIOL is expensive and has high financial conditions of patients, almost all patients pay more attention to the actual visual quality in daily living activities. Therefore, it is a very meaningful research direction for patients' postoperative visual quality to expand samples in researches, combine objective and subjective tests, and organically combine the researches on clinical and functional tests.

\section{References}

1. Hida WT, Motta AF, Nakano CT, Tzelikis PF.Inadvertent implantation of a reversed-optic Tecnis ZM900 multifocal intraocular lens: case report.Arq Bras Oftalmol. 2012 Nov-Dec;75(6):427-9.

2. Dexl AK, Zaluski S, Rasp M, Grabner G.Visual performance after bilateral implantation of a new diffractive aspheric multifocal intraocularlens with a 3.5 D addition.Eur J Ophthalmol. 2014 Jan-Feb;24(1):35-43.

3. Peng C, Zhao J, Ma L, Qu B, Sun Q, Zhang J.Optical performance after bilateral implantation of apodized aspheric diffractive multifocalintraocular lenses with +3.00-D addition power.Acta Ophthalmol. 2012 Dec;90(8):e586-93.

4. Khoramnia R, Auffarth GU, Rabsilber TM, Holzer MP.Implantation of a multifocal toric intraocular lens with a surface-embedded near segment after repeated LASIK treatments.J Cataract Refract Surg. 2012 Nov;38(11):2049-52.

5. Rabsilber TM, Kretz FT, Holzer MP, Fitting A, Sanchez MJ, Auffarth GU.Bilateral implantation of toric multifocal additive intraocular lenses in pseudophakic eyes.J Cataract Refract Surg. 2012 Aug;38(8):1495-8.

6. Agresta B, Knorz MC, Kohnen T, Donatti C, Jackson D.Distance and near visual acuity improvement after implantation of multifocal intraocular lenses in cataract patients with presbyopia: a systematic review.J Refract Surg. 2012 Jun;28(6):426-35. 
7. Lin HT, Chen WR, Ding ZF, Chen W, Wu CR.Clinical evaluation of two multifocal intraocular lens implantation patterns.Int J Ophthalmol. 2012;5(1):76-83.

8. Gayton JL, Mackool RJ, Ernest PH, Seabolt RA, Dumont S.Implantation of multifocal intraocular lenses using a magnification strategy in cataractous eyes with age-related macular degeneration.J Cataract Refract Surg. 2012 Mar;38(3):415-8.

9. Solomon R, Barsam A, Voldman A, Holladay J, Bhogal M, Perry HD, Donnenfeld ED.Argon laser iridoplasty to improve visual function following multifocal intraocular lens implantation.J Refract Surg. 2012 Apr;28(4):281-3.

10. Schmickler S.Postoperative changes in refraction and anterior chamber depth in different multifocalintraocular lenses.J Refract Surg. 2008 Mar;24(3):306-8.

11. Lee ES, Lee SY, Jeong SY, Moon YS, Chin HS, Cho SJ, Oh JH.Effect of postoperative refractive error on visual acuity and patient satisfaction after implantationof the Array multifocal intraocular lens.J Cataract Refract Surg. 2005 Oct;31(10):1960-5.

12. Mesci C, Erbil H, Ozdoker L, Karakurt Y, Bilge AD.Visual acuity and contrast sensitivity function after accommodative and multifocal intraocular lens implantation.Eur J Ophthalmol. 2010 Jan-Feb;20(1):90-100.

13. Woodward MA, Randleman JB, Stulting RD.Dissatisfaction after multifocal intraocular lens implantation.J Cataract Refract Surg. 2009 Jun;35(6):992-7.

14. Kuo IC, Reviglio VE.Wavefront-guided refractive surgery after multifocal lens implantation.Curr Opin Ophthalmol. 2009 Jul;20(4):255-9.

15. McNeely RN, Pazo E, Millar Z, Richoz O, Nesbit A, Moore TC, Moore JE.Threshold limit of postoperative astigmatism for patient satisfaction after refractive lens exchange and multifocal intraocular lens implantation.J Cataract Refract Surg. 2016 Aug;42(8):1126-34.

16. Baig R, A Chaudhry T, Kukreja S, Shakil S, Ahmad K.Patients' satisfaction and spectacle independence after cataract surgery with multifocal intraocular lens implantation in a tertiary care hospital.J Pak Med Assoc. 2016 Jun;66(6):745-7.

17. Chen X, Zhao M, Shi Y, Yang L, Lu Y, Huang Z.Visual outcomes and optical quality after implantation of a diffractive multifocal toric intraocularlens.Indian J Ophthalmol. 2016 Apr;64(4):285-91. 